\title{
Lysophosphatidic Acid Is a Major Serum Noncytokine Survival Factor for Murine Macrophages Which Acts via the Phosphatidylinositol 3-Kinase Signaling Pathway
}

Jason S. Koh, ${ }^{\star}$ Wilfred Lieberthal, ${ }^{\star}$ Stan Heydrick, ${ }^{\ddagger}$ and Jerrold S. Levine*

${ }^{*}$ Renal Section and ${ }^{\ddagger}$ Whitaker Cardiovascular Institute, Department of Medicine, Boston Medical Center, Boston, Massachusetts 02118

\begin{abstract}
Lysophosphatidic acid (LPA) is the smallest and structurally simplest of all the glycerophospholipids. It occurs normally in serum and binds with high affinity to albumin, while retaining its biological activity. The effects of LPA are pleiotropic and range from mitogenesis to stress fiber formation. We show a novel role for LPA: as a macrophage survival factor with potency equivalent to serum. Administration of LPA protects macrophages from apoptosis induced by serum deprivation, and protection is equivalent to that with conventional survival factors such as macrophage colony stimulating factor. The ability of LPA to act as a survival factor is mediated by the lipid kinase phosphatidylinositol 3-kinase (PI3K), since LPA activated both the p85p110 and p110 $\gamma$ isoforms of PI3K and macrophage survival was blocked completely by wortmannin or LY294002, two mechanistically dissimilar inhibitors of PI3K. pp70 downstream kinase activated by PI3K, also contributes to survival, because inhibitors of $\mathrm{pp} 70^{\mathrm{s} 6 \mathrm{k}}$, such as rapamycin, blocked macrophage survival in the presence of LPA. Modified forms of LPA and phospholipids, such as phosphatidylcholine and phosphatidylethanolamine, had no survival effect, thereby showing the specificity of LPA. These results show that LPA acts as a potent macrophage survival factor. Based on striking similarities between our LPA and serum data, we suggest that LPA is a major noncytokine survival factor in serum. (J. Clin. Invest. 1998. 102:716-727.) Key words: apoptosis $\bullet$ lysophosphatidic acid $\bullet$ phosphatidylinositol 3-kinase $\bullet$ macrophages $\bullet$ albumin $\bullet$ phospholipids $\bullet$ survival factors $\cdot$ serum
\end{abstract}

\section{Introduction}

Apoptosis is an energy-requiring form of cell death akin to suicide (1-4). Apoptosis is characterized by cell shrinkage, chromatin condensation, DNA fragmentation, and eventual disintegration into membrane-enclosed apoptotic bodies. Unlike necrotic cell death, which results in loss of membrane integrity and inflammation of surrounding tissues, apoptotic cells main-

Address correspondence to Jerrold S. Levine, Renal Section, E428, Boston Medical Center, One Boston Medical Center Place, Boston, MA 02118. Phone: 617-638-7362; FAX: 617-638-7326; E-mail: jlevine@ bu.edu

Received for publication 23 June 1997 and accepted in revised form 28 May 1998.

J. Clin. Invest.

(C) The American Society for Clinical Investigation, Inc. 0021-9738/98/08/0716/12 \$2.00

Volume 102, Number 4, August 1998, 716-727

http://www.jci.org tain an intact plasma membrane and are rapidly cleared by phagocytes without causing injury to surrounding cells (5).

Apoptosis has been likened to a default pathway in that the apoptotic program is always ready to be executed unless continuously inhibited by extracellular signals called "survival factors" $(2,6)$. The viability of many, if not all, mammalian cells is dependent on specific survival factors. Some examples include: testosterone, which acts on prostatic epithelial cells (7); cytokines such as interleukin-2, which acts on lymphoblasts (8); and growth factors such as macrophage-colony stimulating factor (M-CSF), ${ }^{1}$ which maintains viability of macrophages (9, 10). Nearly all soluble survival factors described to date have been either proteins or steroid-based lipids.

Recently, lysophosphatidic acid (LPA [1-acyl-sn-glycerol3-phosphate]) has received attention as a lipid with growth factor-like effects (11-13). LPA is the smallest and structurally simplest of all glycerophospholipids, and it exists in serum at concentrations of $2-20 \mu \mathrm{M}(14,15)$. LPA is released by activated platelets during blood clotting (14), and immediately complexes with high affinity to serum albumin while retaining its biological activity $(16,17)$. Examples of LPA-mediated actions include platelet aggregation (18), mitogenesis (19-21), and focal adhesion and stress fiber formation (22).

LPA binds to a putative G protein-coupled receptor(s) (GPCR) found on nearly all cell types (23-26). Following G-protein activation, one of the intracellular signaling events that occurs is activation of the lipid kinase phosphatidylinositol 3-kinase (PI3K) (11-13). Yao and Cooper have provided data suggesting that survival factors such as insulin, epidermal growth factor (EGF), and serum act through PI3K to prevent apoptosis (27). Because albumin-bound LPA is thought to be responsible for much of the biological activity of serum, and because LPA signals through PI3K (11-13), we determined whether LPA acts as a survival factor and the extent to which LPA accounts for the survival activity of serum.

We show that LPA alone acts as a potent survival factor for macrophages, and that its actions are mediated through stimulation of PI3K. Based on striking similarities between the effects and potency of LPA and serum, we suggest that LPA is a major noncytokine survival factor in serum. Finally, our findings represent the first report of an LPA-mediated effect on

1. Abbreviations used in this paper: dBSA, $99.95 \%$ delipidated fraction V BSA; GPCR, G protein-coupled receptor; LPA, lysophosphatidic acid; LPG, lysophosphatidylglycerol; M-CSF, macrophage-colony stimulating factor; MTT, 3-(4,5-dimethylthiazol)-2,5-diphenyl tetrazolium bromide; ndBSA, nondelipidated fraction V BSA; NGF, nerve growth factor; PA, phosphatidic acid; PC, phosphatidylcholine; PE, phosphatidylethanolamine; PI3K, phosphatidylinositol 3-kinase; PL, phospholipids; R.0, serum-free RPMI-based medium; R.10, RPMI-based medium supplemented with $10 \%$ FBS; TLCK, tosyllysine chloromethyl ketone; TPCK, tosylphenylalanine chloromethyl ketone. 
macrophages, a cell previously thought to be unresponsive to LPA $(13,28)$.

\section{Methods}

Reagents and cell culture. Peritoneal exudate cells were harvested by lavage from BALB/c mice (The Jackson Laboratory, Bar Harbor, ME) $3 \mathrm{~d}$ after i.p. injection of $1.5 \mathrm{ml}$ of $4.05 \%$ thioglycollate broth (29). Cells were washed twice in RPMI-1640 and plated in 24-well tissue culture plates at $2 \times 10^{5}$ cells/well in R.10 culture medium (RPMI-1640 plus 10\% fetal bovine serum [FBS], with $2 \mathrm{mM} \mathrm{L-glu-}$ tamine, $5 \mathrm{mM}$ HEPES, $100 \mathrm{U} / \mathrm{ml}$ penicillin, and $100 \mu \mathrm{g} / \mathrm{ml}$ streptomycin). After a 4-h incubation at $37^{\circ} \mathrm{C}$, nonadherent cells were removed by washing with RPMI-1640. The remaining adherent cells, $>98 \%$ macrophages, as determined by morphologic examination and nonspecific esterase staining (29), were cultured in R.10, R.0 medium (R.10 minus FBS), or R.0 plus rhM-CSF (a generous gift of the Genetics Institute, Cambridge, MA) or various concentrations of LPA (Sigma Chemical Co., St. Louis, MO). Wortmannin, tosylphenylalanine chloromethyl ketone (TPCK), tosyllysine chloromethyl ketone (TLCK), and rapamycin were from Sigma, and LY294002 was from Biomol (Plymouth Meeting, PA). Suramin was a generous gift from Dr. Wayne Klohs of Parke-Davis (Ann Arbor, MI).

Phospholipids. Phosphatidylcholine (PC [1,2-dioleoyl-sn-glycero3-phosphocholine]) and phosphatidylethanolamine (PE [1,2-dioleoyl$s n$-glycero-3-phosphoethanolamine]) were obtained from Avanti Polar Lipids (Alabaster, AL). L- $\alpha$-lysophosphatidic acid (LPA [1-oleoyl-2hydroxy-sn-glycero-3-phosphate]), L- $\alpha$-lysophosphatidylglycerol (LPG [1-acyl-2-hydroxy-sn-glycero-3-[phospho-rac-1-glycerol]]), L- $\alpha$-phosphatidic acid, dioleoyl (dioleoyl PA [1,2-dioleoyl-sn-glycero-3-phosphate]), L- $\alpha$-phosphatidic acid, dipalmitoyl (dipalmitoyl PA [1,2-dipalmitoyl-sn-glycero-3-phosphate]), and L- $\alpha$-phosphatidic acid, distearoyl (distearoyl PA [1,2-distearoyl-sn-glycero-3-phosphate]) were obtained from Sigma.

Preparation of LPA and phospholipids. $99.95 \%$ delipidated Fraction V BSA (Sigma) was dissolved at $10 \mathrm{mg} / \mathrm{ml}$ in calcium- and magnesium-free phosphate buffered saline (PBS), through which oxygen-free nitrogen had been bubbled for $20 \mathrm{~min}$. LPA and all other phospholipids (PLs) were added to a final concentration of $0.5 \mathrm{mg} / \mathrm{ml}$ $(1.1 \mathrm{mM})$ and stored under argon at $-70^{\circ} \mathrm{C}$. All PLs were made fresh for each experiment and used at a final concentration of $7700 \mathrm{nM}$.

Phase contrast and immunofluorescent microscopy. Nuclear morphology was assessed by staining with H33342 (CalBiochem, San Diego, CA), a supravital DNA dye with an excitation wavelength of 348 $\mathrm{nm}$ and an emission wavelength of $479 \mathrm{~nm}$. H33342 enters live cells and so stains the nuclei of viable, as well as apoptotic and necrotic, cells. The nuclei of apoptotic cells are readily distinguishable from those of viable and necrotic cells on the basis of chromatin condensation, nuclear fragmentation, and increased brightness of H33342 fluorescence (30).

Adherent macrophages and macrophages that had detached spontaneously from culture wells were washed separately in PBS before staining with $\mathrm{H} 33342(1.0 \mu \mathrm{g} / \mathrm{ml})$ for $10 \mathrm{~min}$ at $37^{\circ} \mathrm{C}$. Wet preparations were made on glass slides and examined under phase-contrast and epifluorescence microscopy to visualize cell morphology and H33342 nuclear staining in the same cells.

DNA electrophoresis. Macrophages were cultured for $24 \mathrm{~h}$ in R.0 alone or R.0 plus $10 \%$ FBS, rhM-CSF (100 U/ml), or LPA (7700 nM). Adherent and detached macrophages were pooled for DNA extraction and electrophoresis. To enhance detection of a DNA ladder, low molecular weight DNA was preferentially isolated from cells. Cells were lysed in $0.5 \%$ Triton X-100, $5 \mathrm{mM}$ Tris chloride, $\mathrm{pH} 7.4$, and 20 $\mathrm{mM}$ EDTA for $30 \mathrm{~min}$ at $4^{\circ} \mathrm{C}$. After centrifugation at $15,000 \mathrm{~g}$ for 20 min to eliminate cellular debris and intact chromosomal DNA, supernatants were extracted with phenol-chloroform. Sodium acetate $3.0 \mathrm{M}$, pH 5.2 (1/10 vol), and $1.0 \mathrm{M} \mathrm{MgCl}_{2}(1 / 30 \mathrm{vol})$ were added, and DNA was precipitated in ethanol. Samples were separated by electrophore- sis on a $1.5 \%$ agarose gel containing ethidium bromide. Isolation of low molecular weight DNA is necessary because FBS-deprived macrophages die asynchronously over $72 \mathrm{~h}$.

Thymidine incorporation. Macrophages were cultured for $24 \mathrm{~h}$ in R.0 or R.0 plus FBS, rhM-CSF, or various concentrations of LPA. 2 $\mu \mathrm{Ci}$ of $\left[{ }^{3} \mathrm{H}\right]$ thymidine $(2 \mathrm{Ci} / \mathrm{mmol}$; DuPont/New England Nuclear, Boston, MA) were added for the final $12 \mathrm{~h}$. Cells were washed three times with RPMI-1640 then incubated with $2.0 \mathrm{ml}$ of ice-cold $5 \%$ trichloroacetic acid (TCA) for $1 \mathrm{~h}$ at $4^{\circ} \mathrm{C}$. The TCA was removed, and macrophages were washed once with fresh TCA. $2.0 \mathrm{ml}$ of ice-cold ethanol containing $200 \mu \mathrm{M}$ potassium acetate was added to each well for 5 min, following which cells were incubated twice in $2.0 \mathrm{ml}$ of $3: 1 \mathrm{mix}-$ ture of ethanol/ether at $15 \mathrm{~min}$ per incubation. After air drying, cells were solubilized in $1.0 \mathrm{ml}$ of $0.1 \mathrm{~N} \mathrm{NaOH}$. $\left[{ }^{3} \mathrm{H}\right]$ thymidine counts per minute were measured by adding samples to scintillation fluid and counting using a $\beta$-counter (model 1600TR Tri-Carb liquid scintillation analyzer $\beta$-counter; Packard Instrument Company, Meriden, CT).

MTT assay. Macrophages were cultured for $72 \mathrm{~h}$ in R.0 or R.0 plus FBS, rhM-CSF, or various concentrations of LPA, as well as various inhibitors. The number of viable cells remaining was determined using a modification of the MTT assay (31). This assay is based on the ability of mitochondria from viable cells to cleave the tetrazolium rings of the pale yellow MTT (3-(4,5-dimethylthiazol)-2,5-diphenyl tetrazolium bromide; Sigma) and form a dark blue formazan product. The number of surviving macrophages is directly proportional to the level of the formazan product created. After removing the growth medium, $165 \mu$ l of MTT dissolved in R. $0(1 \mathrm{mg} / \mathrm{ml})$ was added to each well. After incubation at $37^{\circ} \mathrm{C}$ for $4 \mathrm{~h}$, the MTT formazan was dissolved by adding $165 \mu \mathrm{l}$ of $10 \%$ sodium dodecyl sulfate in $0.01 \mathrm{~N} \mathrm{HCl}$. Aliquots from each well were read using a microELISA plate reader (Dynatech, Chantilly, VA) with a test wavelength of $570 \mathrm{~nm}$ and a reference wavelength of $650 \mathrm{~nm}$.

Percent viability was calculated in one of two ways. For construction of an LPA dose-response curve and comparison of the effect of LPA with that of FBS and M-CSF, data are presented as percent increased viability above R.0 and normalized so that culture in R.10 represents $100 \%$, using the formula

$\%$ viability $=\frac{\text { Viability (LPA) }- \text { Viability (R.0) }}{\text { Viability (R.10) }- \text { Viability (R.0) }}$

For all studies using inhibitors of LPA, data are presented as percent viability of that seen with LPA alone in the absence of inhibitor, using the formula

$\%$ viability $=\frac{\text { Viability }(\text { LPA }+ \text { inhibitor })}{\text { Viability }(\text { LPA })}$.

Serum delipidation. Serum was delipidated by one of two protocols. FBS was mixed $1: 1(\mathrm{vol} / \mathrm{vol})$ for $2 \mathrm{~h}$ at $22^{\circ} \mathrm{C}$ with either butanol/ diethyl ether $(1: 4, \mathrm{vol} / \mathrm{vol})(32)$ or chloroform/methanol $(2: 1, \mathrm{vol} / \mathrm{vol})$ (33), and then centrifuged to separate organic and aqueous phases. Residual organic solvents were removed from the delipidated aqueous phase by applying a water-aspirator vacuum for $2 \mathrm{~h}$. The resultant delipidated FBS was sterilely filtered for later use.

$P I 3 K$ assay. Macrophage cell lysates were normalized for protein content, and then incubated for $24 \mathrm{~h}$ with polyclonal anti-PI3K antibodies directed against either the $85-\mathrm{kD}$ regulatory subunit of the p85-p110 isoform (Upstate Biotechnology, Lake Placid, NY) or the $\mathrm{NH}_{2}$ terminus of the p110 $\gamma$ isoform (Santa Cruz Biotechnology, Santa Cruz, CA). Immune complexes were adsorbed onto protein A (p85-

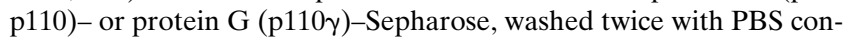
taining $1 \% \mathrm{NP}-40$ and $1 \mathrm{mM} \mathrm{Na}_{3} \mathrm{VO}_{4}$, washed three times with 100 $\mathrm{mM}$ Tris, $\mathrm{pH} 7.4$, containing $5 \mathrm{mM} \mathrm{LiCl}$ and $1 \mathrm{mM} \mathrm{Na}_{3} \mathrm{VO}_{4}$, and finally washed twice with $10 \mathrm{mM}$ Tris, $\mathrm{pH} 7.4$, containing $160 \mathrm{mM}$ $\mathrm{NaCl}, 5 \mathrm{mM}$ EDTA, and $1 \mathrm{mM} \mathrm{Na}_{3} \mathrm{VO}_{4}$. PI3K assays were carried 
out for $10 \mathrm{~min}$ in a buffer containing $10 \mathrm{mM}$ HEPES, pH 7.2, $1 \mathrm{mM}$ EGTA, $20 \mathrm{mM} \mathrm{MgCl} 2,100 \mu \mathrm{M}$ ATP, $10 \mu \mathrm{g}$ of phosphatidylinositol (Avanti Polar Lipids), $20 \mu \mathrm{Ci}$ of $\left[\gamma^{-32} \mathrm{P}\right]$ ATP $(20,000 \mathrm{Ci} / \mathrm{mmol}$; DuPont/NEN). Reactions were run for $10 \mathrm{~min}$ and then stopped by addition of $2 \mathrm{~N} \mathrm{HCl}$. Lipids were extracted, analyzed by TLC, and quantified via $\gamma$-counter liquid scintillation analysis.

Statistics. Quadruplicate wells were examined in each experiment, and the results were averaged. A minimum of three experiments were performed for all data points. Data are expressed as mean \pm SEM of the averaged values obtained from each experiment. Statistical significance was determined by a two-tailed Student's $t$ test.

\section{Results}

LPA acts as a macrophage survival factor. Murine peritoneal macrophages, like most cells in culture, undergo apoptosis upon serum withdrawal $(2,9,10)$. In accord with work by others $(9,10)$, we found that after $72 \mathrm{~h}$ in serum-free medium (R.0) the majority of macrophages exhibited typical features of apoptosis, such as decreased size and cell rounding (Fig. $1 \mathrm{~A}$ ). Despite plating at high density, most of the macrophages in R.0 became nonadherent, detaching gradually over $72 \mathrm{~h}$.
Such progressive loss of cells via detachment is also a characteristic of apoptosis. In marked contrast, macrophages cultured in R.0 plus FBS (R.10), M-CSF (a known macrophage survival factor), or LPA remained fully viable, with extensive spreading and dendritic-like processes (Fig. $1, B-D$ ). Very few macrophages became nonadherent under these conditions. These data suggest that LPA alone can inhibit macrophage apoptosis.

We confirmed LPA's role as a survival factor in two ways. First, DNA electrophoresis of macrophages cultured in R.0 yielded a typical "ladder" pattern of apoptosis, indicative of internucleosomal DNA cleavage (Fig. 2). Culturing macrophages in FBS, LPA, or M-CSF decreased the intensity of the ladder, consistent with inhibition of apoptosis.

Second, adherent and detached macrophages were stained with Hoechst dye (Fig. 3). Many of the remaining adherent cells cultured in R.0 had homogeneous brightly staining nuclei, characteristic of chromatin condensation found in apoptotic cells. Several nuclei had also undergone fragmentation, another unique feature of apoptosis. On phase contrast, these same cells were in general smaller and more rounded, consis-
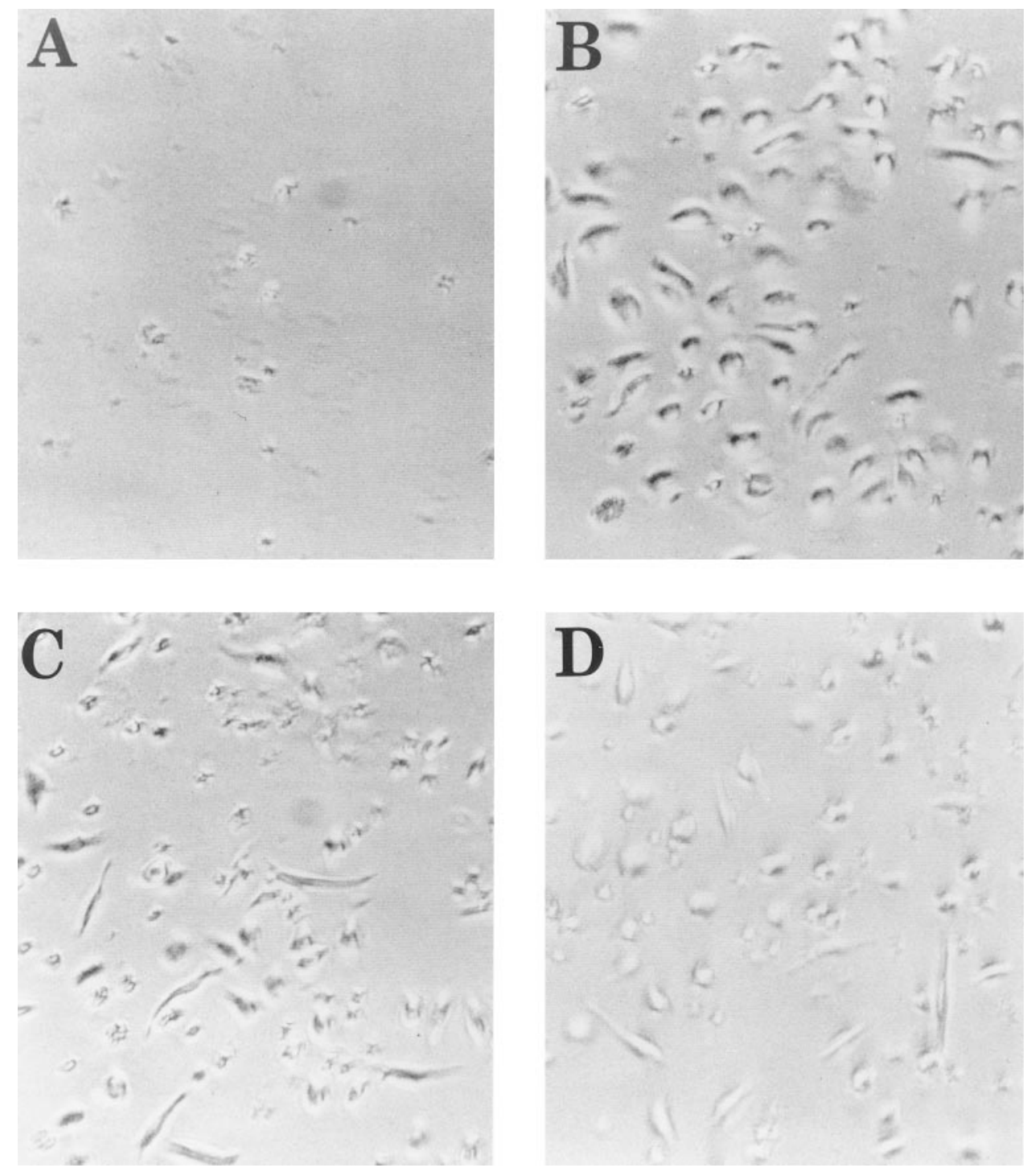

Figure 1. LPA maintains viability of macrophages. Macrophages were cultured for $72 \mathrm{~h}$ in serum-free medium alone (R.0) or supplemented with $10 \%$ FBS (R.10), $100 \mathrm{U} / \mathrm{ml}$ rhM-CSF, and $1200 \mathrm{nM} \mathrm{LPA.} \mathrm{Mac-}$ rophages cultured in R.0 $(A)$ are small and rounded, both characteristic features of apoptosis. Despite initial plating at high density, most cells have become nonadherent and detached. Macrophages cultured in R.10 (B), M-CSF $(C)$, or LPA $(D)$ remain adherent and show dendritic processes typical of healthy macrophages. 


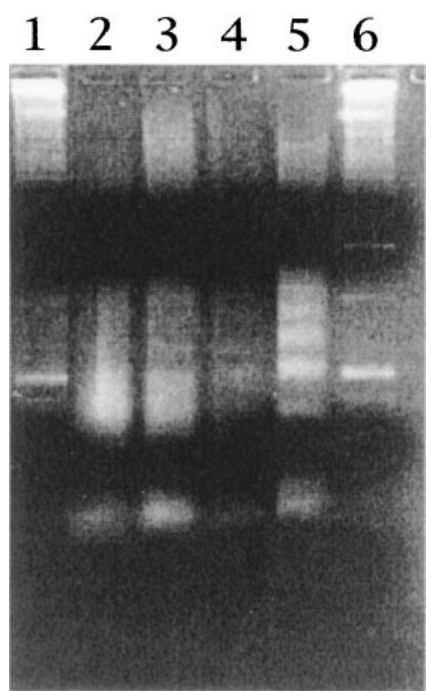

Figure 2. LPA protects cells from apoptosis. DNA electrophoresis was performed on macrophages cultured for $24 \mathrm{~h}$ in R.0 alone and containing $10 \%$ FBS (R.10), $100 \mathrm{U} / \mathrm{ml}$ rhM-CSF, or $7700 \mathrm{nM}$ LPA. (Lanes 1 and 6) DNA size markers. Macrophages cultured in R.0 (lane 5) show a typical "ladder" pattern of cells undergoing apoptosis. Macrophages cultured in M-CSF (lane 2), FBS (lane 3), and LPA (lane 4) show very faint DNA ladder patterns, consistent with inhibition of apoptosis. tent with apoptosis. In marked contrast, macrophages cultured in FBS, M-CSF, or LPA were of normal size and showed the faint nuclear staining, prominent nucleoli, and normal chromatin pattern of viable cells. To confirm that the decrease in cell number seen with R.0 reflects apoptotic cell death and not poor adherence of viable cells, detached macrophages were also stained with Hoechst dye. These cells were uniformly apoptotic, showing decreased size and condensed fragmented nuclei. No detached cells were found for macrophages cultured in FBS, M-CSF, or LPA. Thus, LPA preserves macrophage viability in a manner similar to that of FBS or M-CSF.

To assess the role of LPA as a survival factor more quantitatively, we used the MTT assay (Fig. 4) (31). Preliminary experiments showed that $\sim 25 \%$ of macrophages were viable after FBS deprivation for $72 \mathrm{~h}$, most likely a result of adhesionmediated inhibition of apoptosis (34) (see below). Therefore, data are presented as a percent of increased viability above R.0 and normalized so that culture in R.10 represents $100 \%$ (see Methods). Macrophages were cultured for $72 \mathrm{~h}$ in R.0 plus FBS, M-CSF, or LPA. LPA (7700 nM) was as potent as FBS and M-CSF in maintaining macrophage viability (Fig. $4 A$ ).

We next examined a dose-response curve for the survival activity of LPA (Fig. $4 \mathrm{~B}$ ). This curve had a standard sigmoid shape, with a half-maximal effect at an LPA concentration of $400 \mathrm{nM}$. A significant effect on macrophage viability was seen for concentrations of LPA as low as $50 \mathrm{nM}(P<0.05)$. The effect on viability plateaued at $7700 \mathrm{nM}$. Based on these results, in all subsequent studies, we used an LPA concentration of $7700 \mathrm{nM}$, which is within the physiologic range of LPA.

Solubilization of LPA requires complexing to BSA $(16,17$, 28). Because BSA binds with high affinity to $\operatorname{LPA}(16,17,35)$, we used delipidated BSA (dBSA). Nonetheless, it was still possible that the increased macrophage viability seen with LPA was the result of trace contaminants complexed to dBSA. As a separate control, we therefore supplemented R.0 with dBSA alone at a concentration equivalent to that used in 7700 nM LPA. As shown in Fig. $4 A$, viability with $0.0035 \%$ dBSA (approximately $100 \times$ lower than the final concentration of BSA in R.10) did not differ from viability with R.0. Thus, the survival of macrophages cultured in LPA is due to the LPA itself and not to the dBSA carrier.

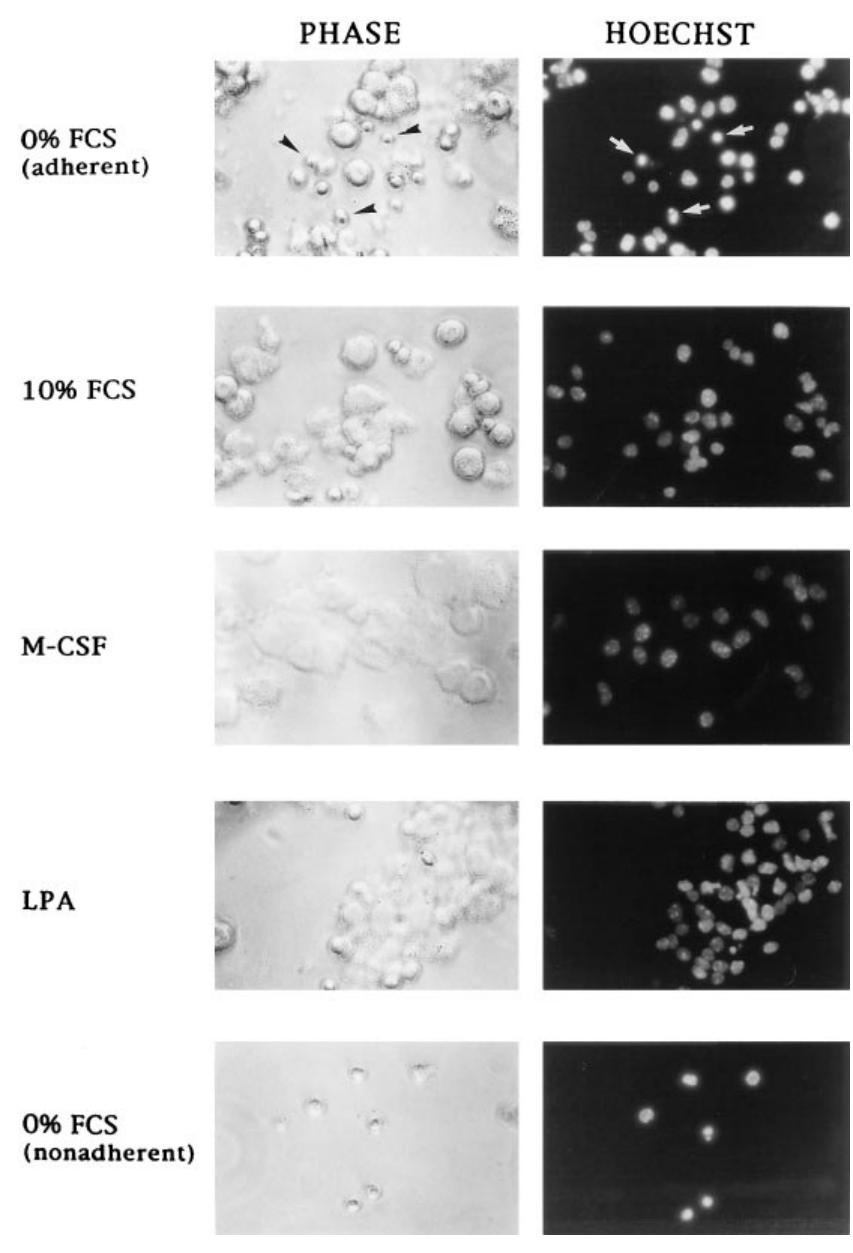

Figure 3. LPA protects cells from apoptosis. Macrophages were cultured in R.0 alone and containing $10 \% \mathrm{FBS}, 100 \mathrm{U} / \mathrm{ml} \mathrm{rhM}-\mathrm{CSF}$, or $7700 \mathrm{nM}$ LPA. After $72 \mathrm{~h}$, the remaining adherent cells were gently scraped and stained with Hoechst dye. Many of the adherent macrophages cultured in R.0 show features of apoptosis. These cells are smaller and more rounded on phase contrast, and their nuclei stain more brightly with Hoechst dye on fluorescence microscopy. The nuclei of apoptotic cells appear as homogeneous masses without discernible nucleoli. Several of these apoptotic nuclei have also undergone fragmentation. The arrows indicate examples of apoptotic cells. Macrophages cultured in FBS, rhM-CSF, and LPA are of normal size and shape, and their nuclei show the faint fluorescence and nucleolar structure of viable cells. Detached macrophages cultured in R.0 are uniformly apoptotic. They are small and rounded, and their nuclei stain brightly with Hoechst dye.

LPA is not a mitogen for macrophage. The increased numbers of viable macrophages seen with LPA could potentially be the result of two mechanisms: inhibition of apoptosis and/or stimulation of proliferation. Although peritoneal macrophages are thought to be terminally differentiated and hence nonproliferative (36), LPA stimulates proliferation in a variety of cell types (11-13, 19-21). Therefore, we assessed the contribution of LPA-induced proliferation to increased macrophage viability by measuring $\left[{ }^{3} \mathrm{H}\right]$ thymidine incorporation as an index of DNA synthesis (Fig. 5). Macrophages were cultured for $24 \mathrm{~h}$ in R.0 or R.0 plus FBS, M-CSF, or LPA, with $\left[{ }^{3} \mathrm{H}\right]$ thymidine added for the final $12 \mathrm{~h}$. Data are presented as percent change in $\left[{ }^{3} \mathrm{H}\right]$ thymidine incorporation compared with R.10. As ex- 

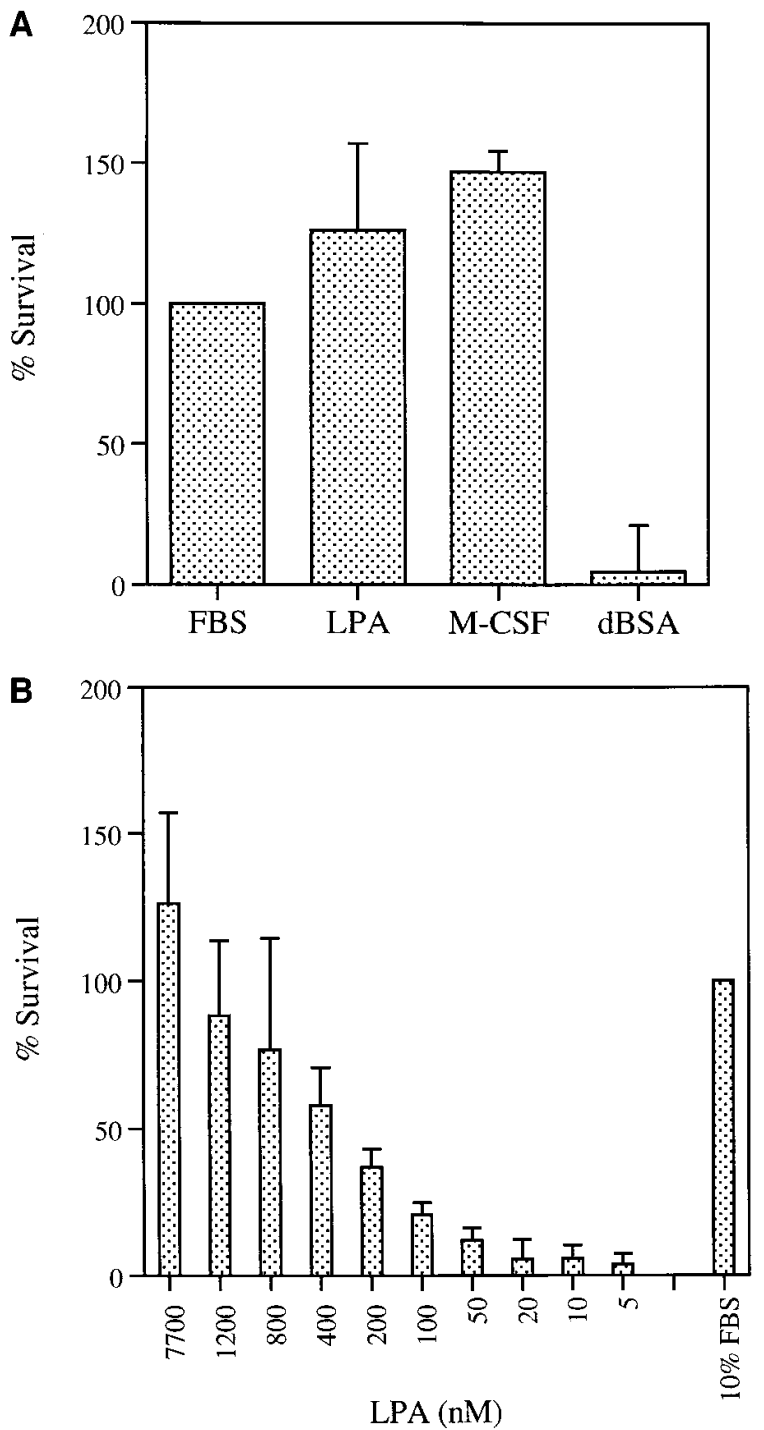

Figure 4. LPA is a survival factor for macrophages. $(A)$ Macrophages were cultured for $72 \mathrm{~h}$ in serum-free medium alone (R.0) and containing $10 \%$ FBS (R.10), $100 \mathrm{U} / \mathrm{ml}$ rhM-CSF, $7700 \mathrm{nM}$ LPA complexed to $0.0035 \%$ delipidated BSA (dBSA), or $0.0035 \%$ dBSA alone. Relative cell number was determined by MTT assay. $P<0.005$, LPA compared with R.0; $P<0.005$, M-CSF compared with R.0; $P>0.5$, LPA compared with R.10 or M-CSF; $P>0.5,0.0035 \%$ dBSA compared with R.0. (B) Macrophages were cultured for $72 \mathrm{~h}$ in R.0 plus various doses of LPA, and viability was determined by MTT assay.

pected, essentially no $\left[{ }^{3} \mathrm{H}\right]$ thymidine incorporation was seen with R.0. M-CSF had a weak but significant proliferative effect, whereas LPA at concentrations up to $7700 \mathrm{nM}$ did not increase $\left[{ }^{3} \mathrm{H}\right]$ thymidine incorporation above that seen with R.0 $(P>0.5)$. We conclude that LPA is not a mitogen for macrophages, and hence LPA maintains macrophage viability solely through inhibition of apoptosis.

To show directly the nonproliferative nature of macrophages, we determined $\left[{ }^{3} \mathrm{H}\right]$ thymidine incorporation in the presence and absence of mitomycin C, a DNA cross-linking agent that inhibits cell proliferation (Table I). Absolute values for $\left[{ }^{3} \mathrm{H}\right]$ thymidine incorporation by macrophages cultured with LPA are very similar to background values seen with mitomycin $\mathrm{C}$. The nonproliferative nature of macrophages is under-

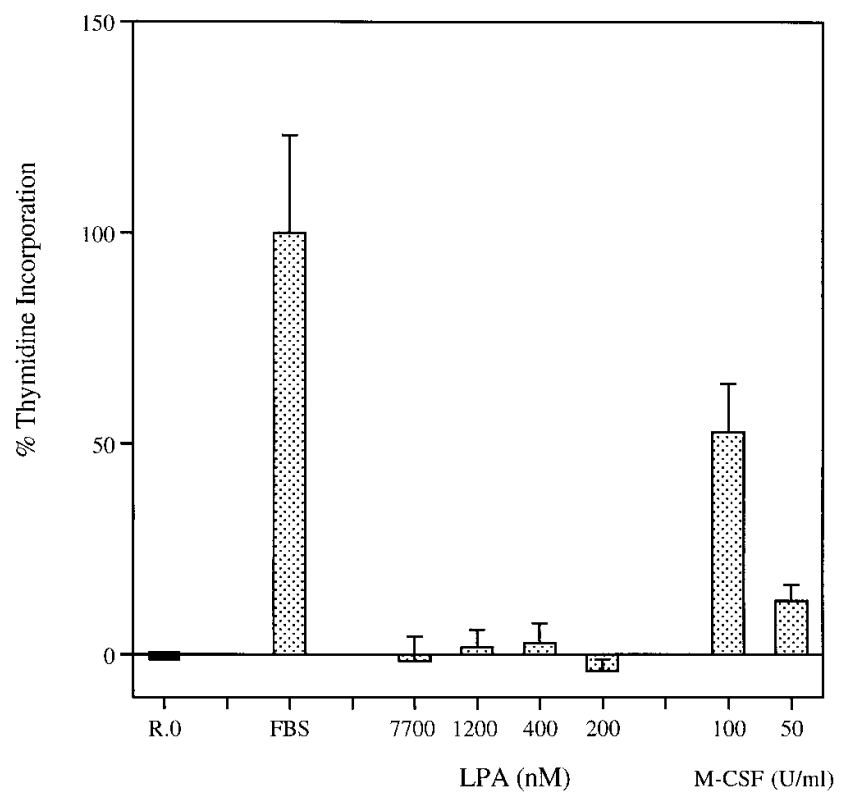

Figure 5. LPA is not a mitogen for macrophages. Macrophages were cultured for $24 \mathrm{~h}$ in R.0 alone and R.0 containing 10\% FBS (R.10), 50 and $100 \mathrm{U} / \mathrm{ml} \mathrm{rhM}-\mathrm{CSF}$, or 200, 400, 1,200, and 7,700 nM LPA.

$\left[{ }^{3} \mathrm{H}\right]$ thymidine incorporation was determined during the final $12 \mathrm{~h}$. Data are presented as percent change in $\left[{ }^{3} \mathrm{H}\right]$ thymidine incorporation compared with R.10. $P<0.01$, R.10 and M-CSF $(100 \mathrm{U} / \mathrm{ml})$ compared with R.0; $P>0.5$, LPA at all concentrations compared with R.0.

scored by comparison with a well-described proliferating cell such as the Chinese hamster ovary $(\mathrm{CHO})$ cell line. Even in the presence of FBS, $\left[{ }^{3} \mathrm{H}\right]$ thymidine incorporation by macrophages is $<1 \%$ of that for $\mathrm{CHO}$ cells. These findings show directly that macrophages are nonproliferative. Thus, even in the case of FBS, the increased number of viable macrophages is predominantly the result of inhibition of apoptosis rather than stimulation of proliferation.

Suramin blocks LPA-mediated macrophage survival. Suramin is a membrane impermeant polyanionic napthalenesulfonic acid derivative and broad-specificity inhibitor of ligand-receptor interactions, which strongly inhibits the bind-

Table I. Peritoneal Macrophages Are Nonproliferative

\begin{tabular}{clc}
\hline \multicolumn{1}{c}{ Cell type } & \multicolumn{1}{c}{ Culture medium } & {$\left[{ }^{3} \mathrm{H}\right]$ Thymidine incorporation } \\
\hline & & $c p m$ \\
Peritoneal & & \\
macrophages & R.0 & $161 \pm 10$ \\
& R.10 & $1239 \pm 181$ \\
& R.0 + mitomycin C & $23 \pm 2$ \\
& R.10 + mitomycin C & $21 \pm 5$ \\
CHO cells & LPA (7700 nM) & $129 \pm 8$ \\
& R.10 & $159075 \pm 13997$ \\
\hline
\end{tabular}

Equal numbers of macrophages or $\mathrm{CHO}$ cells were cultured for $24 \mathrm{~h}$ in R.0 alone or supplemented with $10 \%$ FBS (R.10) or $7700 \mathrm{nM} \mathrm{LPA}$, in the presence or absence of mitomycin $\mathrm{C}(25 \mu \mathrm{g} / \mathrm{ml})$. $\left[{ }^{3} \mathrm{H}\right]$ Thymidine incorporation was determined during the final $12 \mathrm{~h}$. Data are presented as mean \pm SEM of the absolute values of the counts per minute. 


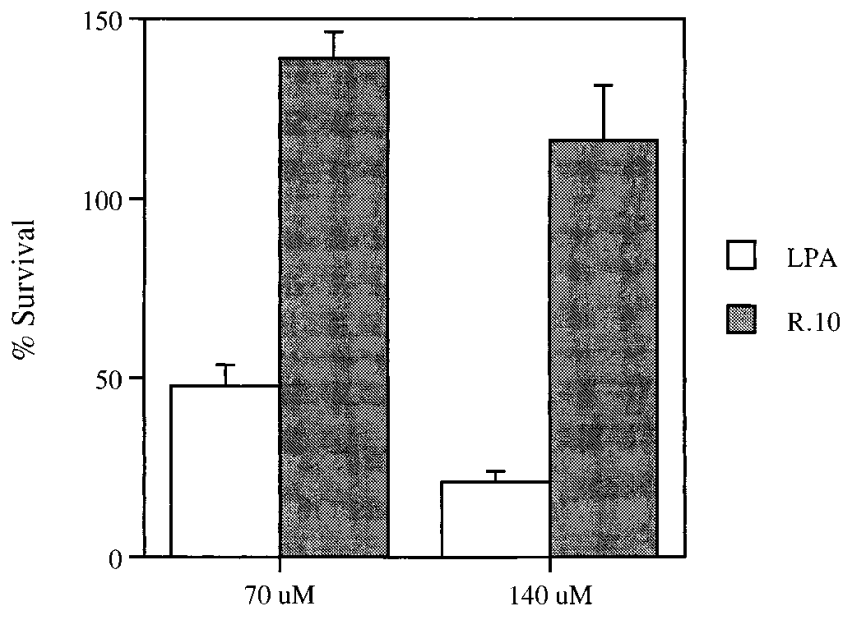

[Suramin]

Figure 6. Suramin blocks LPA-mediated macrophage survival. Macrophages were cultured for $72 \mathrm{~h}$ in R.10 or R.0 plus $7700 \mathrm{nM} \mathrm{LPA}$ and the indicated concentrations of suramin. Cell viability was assessed with the MTT assay. Data are presented as percent response of that for LPA or R.10 in the absence of suramin. $P<0.0001$, LPA vs. LPA plus suramin $(70$ and $140 \mu \mathrm{M}) ; P<0.001$, R.10 vs. R.10 plus suramin $(70 \mu \mathrm{M}) ; P>0.3$, R.10 vs. R.10 plus suramin $(140 \mu \mathrm{M})$.

ing of LPA to its putative receptor $(21,23,37)$. To confirm that LPA promotes survival in a receptor-specific manner, we cultured macrophages for $72 \mathrm{~h}$ in R.0 plus LPA and suramin. Suramin inhibited survival with an $\mathrm{IC}_{50}$ of $\sim 70 \mu \mathrm{M}$, similar to published values for inhibition of LPA-induced proliferation $(21,37)$ (Fig. 6). To exclude the possibility that suramin is toxic to macrophages, we coincubated identical concentrations of suramin with FBS and found no inhibition of survival (Fig. 6). The failure of suramin to inhibit FBS-mediated survival of macrophages is not surprising because the $\mathrm{IC}_{50}$ of suramin for inhibition of protein growth factors in FBS varies depending on the cell type $(21,37)$. For example, in the case of Rat-1 fibroblasts, the $\mathrm{IC}_{50}$ of suramin for EGF is 500-fold greater than that for LPA (21). Thus, addition of suramin to FBS has no effect on macrophage survival because suramin inhibits the effects of LPA but not those of other survival factors such as platelet-derived growth factor (PDGF) and insulin-like growth factor-1 (IGF-1). Taken together, these data are consistent with the hypothesis that LPA acts as a survival factor via interaction with its putative membrane receptor.

Other structurally related PLs do not promote macrophage survival. To show the specificity of LPA as a survival factor, we tested the effects of several other PLs. Various forms of PA (which differ from LPA by the presence of a fatty acid at the $s n$-2 position of the glycerol backbone) were all less effective than LPA in promoting macrophage survival. Survival with PA was greatest for dioleoyl PA and least for dipalmitoyl PA (Fig. 7). These results are in agreement with reports comparing the proliferative abilities of LPA with various types of PA in nonmacrophage cell types (21). It is unclear whether PA interacts with a receptor of its own or cross-reacts with the LPA receptor (11-13).

LPG, which is structurally similar to LPA except for a glycerol moiety attached to the 3-phosphate head group, has no survival effect (Fig. 7). Similarly, PLs such as PE and PC

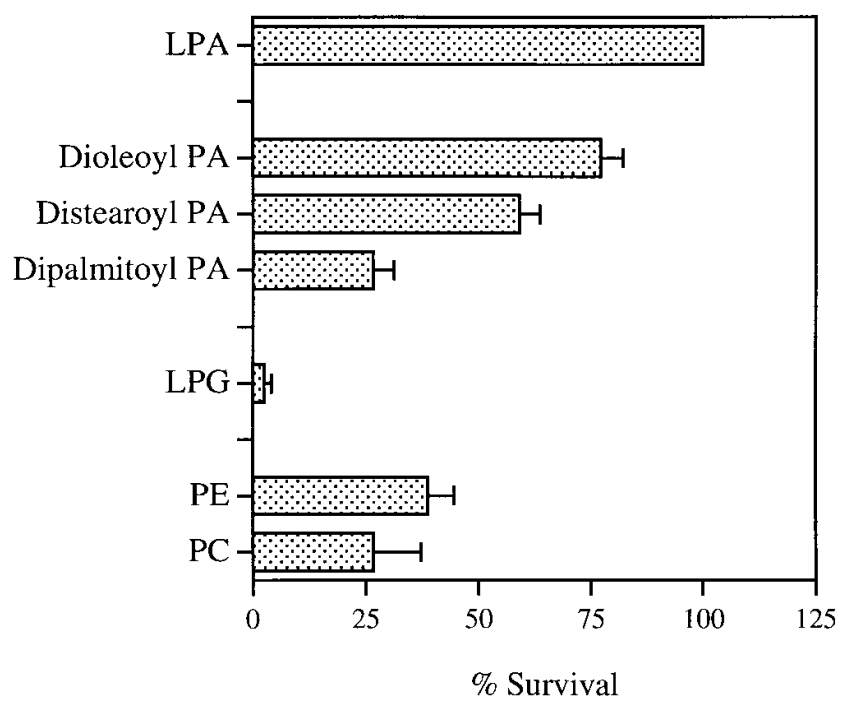

Figure 7. The effect of PL other than LPA on macrophage survival. Macrophages were cultured for $72 \mathrm{~h}$ in R.0 plus each of the following PL, all at $7700 \mathrm{nM}$ : LPA; dioleoyl phosphatidic acid (PA); distearoyl PA; dipalmitoyl PA; lysophosphatidylglycerol (LPG); phosphatidylethanolamine (PE); and phosphatidylcholine (PC). Cell viability was assessed with the MTT assay. Data are presented as percent response of that for LPA. $P<0.0001$, LPA vs. all PL.

showed minimal survival factor ability. These results plus those with suramin provide independent evidence that LPA promotes macrophage survival through interaction with a specific receptor.

LPA-mediated survival occurs through activation of PI3K. Several groups have shown that activation of PI3K is linked to inhibition of apoptosis $(27,38,39)$. Because LPA is known to activate PI3K (11-13), we investigated the contribution of PI3K to LPA-mediated macrophage survival.

In these studies, we used wortmannin and LY294002, two potent and structurally different inhibitors of PI3K $(27,40,41)$. Macrophages were cultured for $72 \mathrm{~h}$ in R.0 plus LPA and wortmannin (Fig. 8 A) or LY294002 (Fig. 8 B). Both wortmannin and LY294002 inhibited the effect of LPA on macrophage survival in a dose-dependent manner. The $\mathrm{IC}_{50}$ 's for inhibition of survival by wortmannin $(\sim 50 \mathrm{nM})$ and LY294002 $(\sim 1.4 \mu \mathrm{M})$ are consistent with their potency as PI3K inhibitors $(27,40$, 41). These data support a role for PI3K in the survival effect of LPA on macrophages. The fact that wortmannin and LY294002 are structurally distinct and inhibit PI3K by different mechanisms $(27,40,41)$ suggests that LPA-induced viability is the result of inhibition of PI3K rather than a nonspecific effect.

We next showed that LPA induces PI3K activity in macrophages. Macrophages were FBS starved for $6 \mathrm{~h}$, and then stimulated with LPA. LPA activated the p85-p110 isoform of PI3K within 2 min of stimulation, with peak activity occurring at 5 min (Fig. $9 A$ ). Preculture of macrophages with wortman$\operatorname{nin}(1 \mu \mathrm{M})$ or LY294002 $(100 \mu \mathrm{M})$ led to near maximal inhibition of p85-p110 PI3K activity (Fig. $9 \mathrm{~B}$ ). These same concentrations of wortmannin and LY294002 almost completely inhibited the survival activity of LPA (Fig. $8 A$ and $B$ ). Stimulation with LPA also induced activation of the p110y isoform of PI3K (Fig. $9 \mathrm{D}$ ). We conclude that, as for other growth factors $(27,38,39)$, the survival activity of LPA is largely mediated through PI3K. 


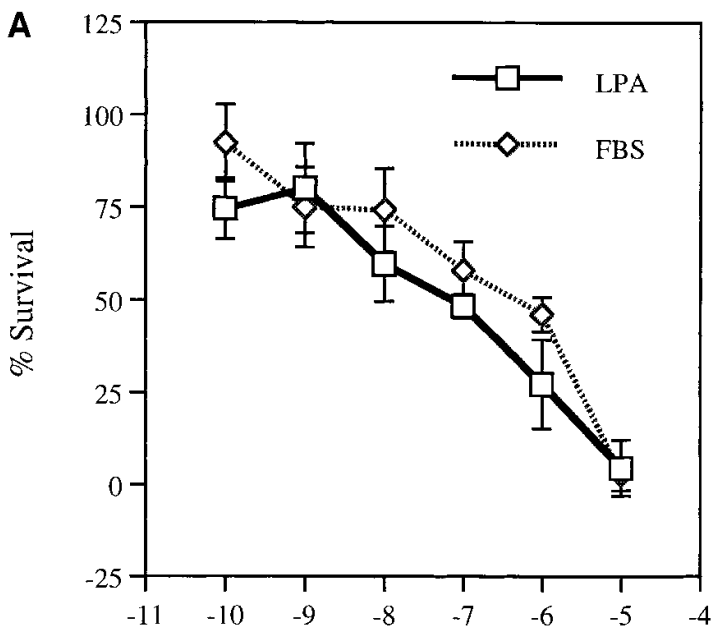

$\log$ [wortmannin, Molar]

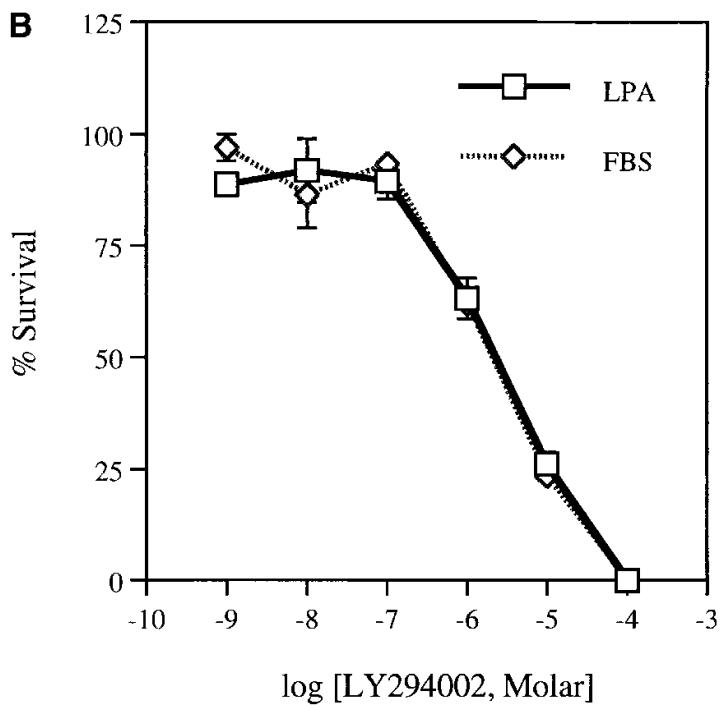

Figure 8. PI3K is necessary for LPA- and FBS-mediated macrophage survival. Macrophages were cultured for $72 \mathrm{~h}$ in R.10 (dotted lines) or R.0 plus $7700 \mathrm{nM}$ LPA (solid lines) and the indicated concentrations of the PI3K inhibitors wortmannin $(A)$ and LY294002 (B). Cell viability was assessed with the MTT assay. Data are presented as percent response of that for LPA or R.10 in the absence of inhibitor. The differences in percent viability between LPA and R.10 were not significant at any concentration of wortmannin $(P>0.25)$ or LY294002 $(P>0.9)$.

We next determined the ability of wortmannin and LY294002 to inhibit the survival activity of FBS (Fig. 8, $A$ and $B)$. The dose-response curve for LY294002 and FBS was virtually identical to that for LY294002 and LPA. Although the wortmannin concentrations required to induce apoptosis were arithmetically higher for FBS than for LPA, these differences were not statistically significant at any wortmannin concentration. Thus, our data differ from those of Yao and Cooper (27), in which 10-fold higher concentrations of wortmannin were needed to inhibit the survival effect of FBS compared with survival factors such as insulin and EGF. The striking similarity of the dose-response curves for each PI3K inhibitor in the presence of LPA versus FBS offers strong support for the hypothesis that LPA contributes prominently to the survival activity of FBS.

\section{A LPA}

Om 2m 5m 10m

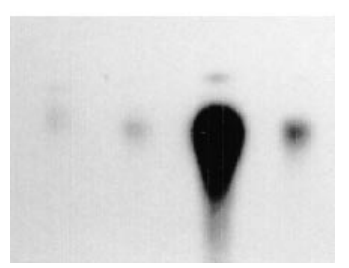

\section{B

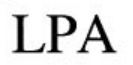

LPA

\section{Wortmannin}

0m 5m

0m 5m 0m 5m

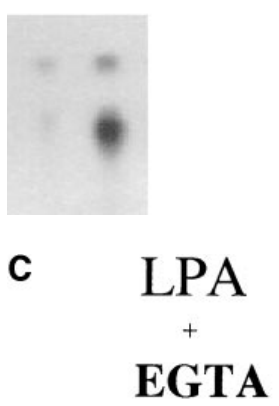

OmM 5mM 10mM

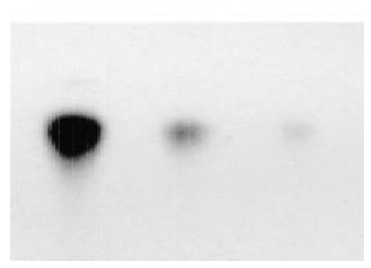

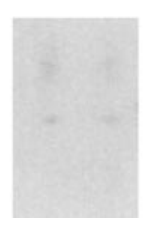

D LPA

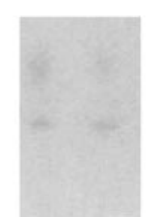

LPA $+$

LY294002

Figure 9. Stimulation of macrophages with LPA activates PI3K. Macrophages were precultured for $6 \mathrm{~h}$ in either R.0 $(A$ and $D)$, R.0 plus wortmannin $(1 \mu \mathrm{M})$ or LY294002 $(100 \mu \mathrm{M})(B)$, or R.0 plus EGTA at the indicated concentrations $(C)$. Following preculture, macrophages were stimulated with LPA $(7700 \mathrm{nM})$ for $5 \min (C)$ or the indicated times $(A, B$, and $D)$. p85-p110 $(A, B$, and $C)$ or p110 $\gamma$ $(D)$ PI3K activity was determined as described in the Methods.

Finally, it may be noted that FBS-starved macrophages have a low but detectable level of PI3K activity (Fig. $9 A$ ). As noted above, we hypothesize that this baseline PI3K activity is responsible for the $25 \%$ survival seen after $72 \mathrm{~h}$ of FBS-free culture. To determine whether adhesion-mediated signaling events are responsible for baseline PI3K activity, as shown in other cell types (42-44), macrophages were precultured in EGTA to chelate $\mathrm{Ca}^{2+}$ and block adhesion. EGTA not only inhibited baseline PI3K activity (data not shown) but also prevented activation of PI3K by LPA (Fig. $9 C$; see Discussion).

LPA-mediated survival is signaled only partly through $p p 70^{s 6 k}$. Given the key role of PI3K, we examined the contribution of pp $70^{\text {s6k }}$, a downstream kinase activated by PI3K (45, 46). pp70 $70^{\mathrm{s} k \mathrm{k}}$ is activated by almost all mitogens and plays an im- 


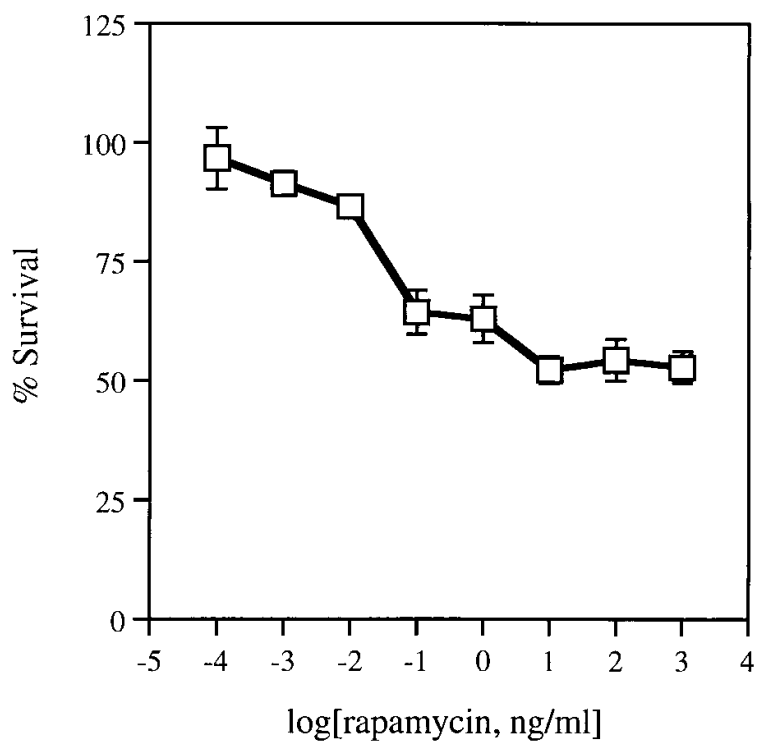

Figure 10. Inhibition of $\mathrm{pp} 70^{\mathrm{s} 6 \mathrm{k}}$ by rapamycin partially blocks LPAmediated macrophage survival. Macrophages were cultured for $72 \mathrm{~h}$ in R.0 plus $7700 \mathrm{nM}$ LPA and the indicated concentrations of rapamycin. Cell viability was assessed with the MTT assay. Data are presented as percent response of that for LPA in the absence of rapamycin.

portant role in progression through early phases of the cell cycle (46).

Complete inhibition of LPA-mediated survival was not possible with the immunosuppressant rapamycin, a highly specific and potent inhibitor of pp70 $0^{\mathrm{s} k \mathrm{k}}$ activation (Fig. 10) (47). Even at rapamycin concentrations 100 -fold greater than those needed to inhibit completely the activity of $\mathrm{pp} 70^{56 \mathrm{k}}(47)$, LPAmediated survival was inhibited by only about $50 \%$. We conclude that a part, but not all, of the survival value of PI3K activation is mediated via $\mathrm{pp} 70^{56 \mathrm{k}}$, and that other downstream mediators of PI3K, including the serine-threonine kinase Akt $(44,48-50)$, are involved in LPA signaling as well.

We extended these results using two other inhibitors of pp70 $7{ }^{\mathrm{s} k \mathrm{k}}$, the serine protease inhibitors TPCK and TLCK, whose mechanism of action differs from that of rapamycin (51). Surprisingly, not only were TPCK (Fig. $11 A$ ) and TLCK (Fig. $11 B$ ) able to inhibit completely LPA-mediated survival, but their dose-response curves yielded $\mathrm{IC}_{50}$ 's $(0.4 \mu \mathrm{M}$ and 0.15 $\mu \mathrm{M}$, respectively) well below published values for inhibition of pp70 ${ }^{\text {s6k }}$ (5 and $50 \mu \mathrm{M}$, respectively). Because TPCK/TLCK and rapamycin have similar but not identical inhibitory effects, our data suggest that one of the non-pp $70^{\mathrm{s} 6 \mathrm{k}}$ signaling pathways inhibited by TPCK or TLCK (e.g., phosphorylation of IкB [51]) may mediate some of the survival effects of LPA not signaled through $\mathrm{pp} 70^{\mathrm{s} 6 \mathrm{k}}$.

$B S A$ alone can act as a survival factor. Albumin serves two functions for LPA. First, it acts as a carrier to solubilize LPA, without affecting biologic potency $(16,17)$, and, second, it increases the physiologic half-life of LPA by protecting it from degradation by phospholipases (13). Thus, LPA bound to BSA within FBS may have profound effects on cell survival.

To examine this issue, we added nondelipidated BSA (ndBSA) or $99.95 \%$ dBSA to macrophages cultured in FBSfree medium and compared their effect on survival to that of FBS. We chose $0.1 \%(\mathrm{wt} / \mathrm{vol})$ as representative of the BSA

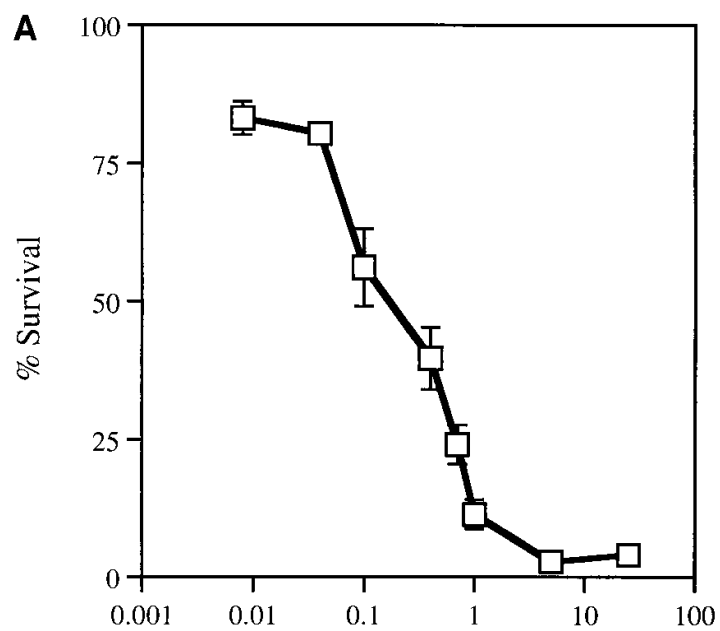

[TPCK, uM]

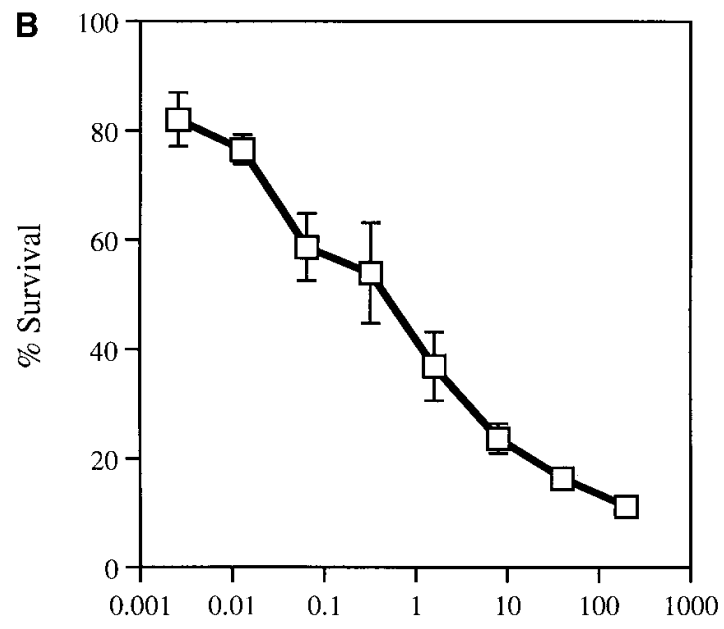

[TLCK, uM]

Figure 11. Inhibition of $\mathrm{pp} 70^{\mathrm{s} 6 \mathrm{k}}$ by TPCK and TLCK completely blocks LPA-mediated macrophage survival. Macrophages were cultured for $72 \mathrm{~h}$ in R.0 plus $7700 \mathrm{nM}$ LPA and the indicated concentrations of TPCK $(A)$ or TLCK $(B)$. Cell viability was assessed with the MTT assay. Data are presented as percent response of that for LPA in the absence of inhibitor.

concentration achieved with $10 \%$ FBS. As shown in Fig. $12 \mathrm{~A}$, ndBSA was a potent survival factor, with macrophages cultured in the presence of ndBSA having nearly equivalent survival compared with $10 \%$ FBS. Surprisingly, dBSA was also a potent survival factor, though its effect was significantly less than that of ndBSA $(P<0.01)$. The effect of dBSA on survival suggests that albumin may have survival activity independent of bound lipids. Addition of suramin $(140 \mu \mathrm{M})$ had no effect on the survival activity of dBSA (data not shown), implying that survival cannot be attributed to incomplete delipidation of dBSA. It should be noted that the final concentration of dBSA used in all our LPA studies was $0.0035 \%$ ( $>100$ times lower than that used in Fig. 12 A), and that this lower concentration of dBSA had no effect on macrophage survival (Fig. $4 A$ ).

Finally, to examine directly the role of serum lipids, we compared the survival activity of FBS to that of dFBS. As 


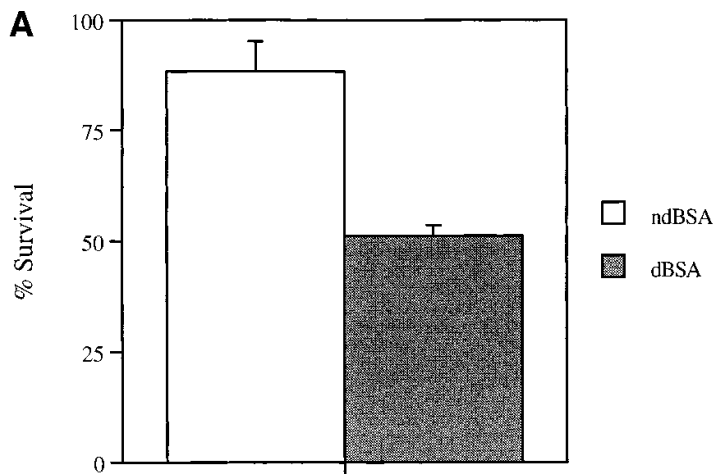

$0.1 \% \mathrm{BSA}(\mathrm{w} / \mathrm{v})$

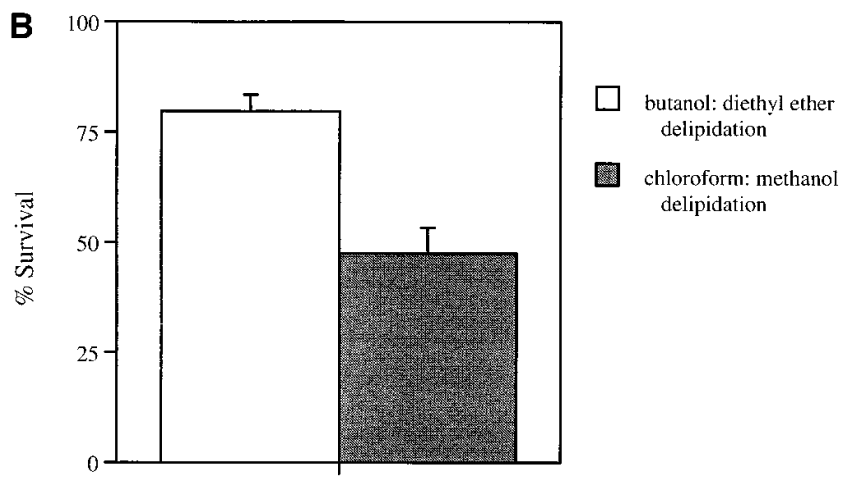

$10 \%$ delipidated FBS

Figure 12. Serum lipids have a potent influence on macrophage survival. Macrophages were cultured for $72 \mathrm{~h}$ in R.10 or $(A)$ R.0 plus nondelipidated (ndBSA) and $99.95 \%$ delipidated (dBSA) BSA at the indicated concentration (wt/vol) or (B) R.0 plus $10 \%$ delipidated FBS produced by two different protocols. Cell viability was assessed with the MTT assay. Data are presented as percent response of that for R.10. $P<0.0001$, dBSA and ndBSA compared with R. $0 ; P<0.01$, dBSA compared with ndBSA; $P<0.02$, delipidated FBS compared with FBS.

shown in Fig. $12 B$, delipidated FBS had only $50-80 \%$ of the survival activity of untreated FBS $(P<0.02)$. To ensure that delipidation did not adversely affect nonlipid components of FBS, we used two different protocols for delipidation with comparable results $(32,33)$. Moreover, macrophages cultured in dFBS behaved normally with respect to several well-characterized macrophage functions, including cytokine production, adhesion, and phagocytosis (data not shown). Together, these data suggest that LPA, and perhaps other lipids, represent potent noncytokine survival factors in FBS.

\section{Discussion}

Our primary objective was to examine the role of LPA as a macrophage survival factor. LPA is a glycerophospholipid present in serum at micromolar concentrations with a pleiotropic range of effects (11-13). LPA activates PI3K (11-13), an important signaling event for survival factors such as EGF and insulin $(27,38,39)$. Thus, it seemed likely that LPA would act as a survival factor. Despite the breadth of research focusing on LPA, the effect of LPA as a survival factor has not been reported. This may be because most studies on LPA have used proliferating cells, such as fibroblasts, in which the mitogenic effect of LPA can obscure any effects of LPA on apoptosis (11-13). This problem does not exist for peritoneal macrophages, which are terminally differentiated and nonproliferative (see Fig. 5 and Table I) (36). Thus, assessing the role of LPA as a survival factor was greatly simplified in our studies, because cells had only two possible fates: survival or apoptosis.

We report several novel findings. First, we provide evidence that LPA alone is a potent macrophage survival factor and that albumin-bound LPA is a key survival factor in serum. Because all survival factors described to date are proteins or steroid-based lipids, LPA represents a new class of cell survival factors. Second, LPA-mediated survival is dependent on activation of PI3K. Third, one of the downstream mediators of survival signaling by $\mathrm{PI} 3 \mathrm{~K}$ is the kinase $\mathrm{pp} 70^{\mathrm{s} 6 \mathrm{k}}$. Since inhibition of pp70 $0^{\mathrm{s} 6 \mathrm{k}}$ only partially blocks LPA-mediated survival, other mediators of PI3K, in addition to $p p 70^{s 6 \mathrm{k}}$, must be involved in survival signaling by LPA.

Macrophages cultured in LPA or FBS are morphologically similar. They spread and form stellate processes and remain viable as assessed by DNA electrophoresis and Hoechst staining. Coincubation with suramin, which blocks binding of LPA to its putative receptor $(21,23,37)$, induces macrophage apoptosis, implying that LPA promotes macrophage survival through a receptor-mediated process. The failure of several structurally similar PLs to promote survival indicates that the effect of LPA is specific. Despite earlier reports of macrophage nonresponsiveness to LPA, macrophage survival was seen at concentrations as low as $50 \mathrm{nM}$, placing it within the range of the most sensitive LPA responses (11-13).

BSA alone has been reported to have survival activity (5254). One explanation for this is that ndBSA contains high concentrations of LPA $(16,17,35)$. We found significant macrophage survival with LPA concentrations as low as $50 \mathrm{nM}$, so it is clear that even trace contamination of BSA with LPA can have a substantial effect on cell survival. In fact, at concentrations equivalent to those found in $10 \% \mathrm{FBS}$, ndBSA had a survival effect rivaling that of FBS. Although we believe LPA is the key factor responsible for the survival value of BSA, other lipids, such as fatty acids (35), which also bind with high-affinity to BSA, cannot be discounted.

Binding of LPA to its putative GPCR leads to activation of PI3K (11-13, 55). This lipid kinase is involved in LPA-mediated proliferation of fibroblasts (55) and plays a critical role in survival factor signaling by EGF, insulin, and FBS $(27,38,39)$. Most PI3K isoforms are composed of an $85-\mathrm{kD}$ regulatory subunit and a $110-\mathrm{kD}$ catalytic subunit (56). PI3K is activated by both receptor tyrosine kinases (RTKs), like those for EGF and insulin, and GPCR, like that for LPA. Activation of PI3K by RTK occurs following recruitment of the $85-\mathrm{kD}$ regulatory subunit to the receptor complex. Activation of PI3K by GPCR is thought to occur via targeted interaction of the recently cloned p110 $\gamma$ isoforms of PI3K with the $\beta \gamma$ subunit of GPCR (57-62). p110y differs from other PI3K isoforms in that it does not associate with a p 85 regulatory subunit and is less sensitive to inhibition by wortmannin $(58,59)$.

Our data imply that PI3K activation is essential for LPAmediated survival of macrophages. Stimulation of FBS-starved macrophages with LPA led to rapid induction of PI3K activity (Fig. 9). The two PI3K inhibitors, wortmannin and LY294002, inhibited LPA-induced PI3K activity and completely blocked survival of LPA-stimulated macrophages. At the concentra- 
tions used in our studies, both inhibitors are very specific for PI3K $(27,40,41)$. The fact that these two inhibitors are structurally dissimilar suggests that inhibition of survival is specific to their effect on PI3K and not the result of nonspecific effects on other signaling pathways $(40,41)$.

Our studies do not elucidate the signaling pathways by which LPA activates PI3K. Somewhat surprisingly, given recent reports suggesting that GPCRs, including the LPA receptor, signal through the p110y isoform $(56,57,59,60,62)$, we detected LPA-mediated activation of both the p85-p110 and p110 $\gamma$ isoforms. LPA-mediated activation of p85-p110 PI3K occurred only in adherent macrophages and was blocked in macrophages precultured in EGTA (Fig. 9). It is tempting to speculate that LPA-mediated signaling events, perhaps occurring through Ras $(44,63)$, synergize with integrin-mediated activation of p85-p110, occurring through the tyrosine kinase FAK (42-44). The failure of LPA to activate p85-p110 in nonadherent macrophages is consistent with recent reports showing that transduction through several signaling pathways is incomplete or even inhibited in nonadherent cells $(42,64-66)$.

LPA-induced activation of p110y is consistent with two features of our results. First, LPA also promoted the survival of macrophages cultured in the presence of EGTA (data not shown), in which activation of p85-p110 was inhibited (Fig. 9). Second, the $\mathrm{IC}_{50}$ of wortmannin for inhibition of LPA-mediated survival is consistent with signaling by LPA through p110 $\gamma$. This isoform requires approximately 10-fold higher concentrations of wortmannin for inhibition than does p85p110 (59). Most studies using wortmannin have reported $\mathrm{IC}_{50}$ values in the range of $1-5 \mathrm{nM}(27,40)$. Our value of $50 \mathrm{nM}$ is more in accord with those reported for p110y.

After activation, PI3K signals through a variety of kinases, including pp70 ${ }^{\mathrm{s} 6 \mathrm{k}}(46)$, Akt $(67,68)$, p65 $5^{\mathrm{PAK}}(46)$, and nonconventional isoforms of protein kinase $\mathrm{C}(69,70)$. Because pp70 $7{ }^{\mathrm{s} 6 \mathrm{k}}$ has an important role in mRNA synthesis and cell growth $(46,71)$, we examined the contribution of $p p 70^{\mathrm{s} 6 \mathrm{k}}$ to LPA-induced macrophage survival. Although an extremely potent and specific inhibitor of $p p 70^{\mathrm{s} 6 \mathrm{k}}(47,72)$, rapamycin inhibited LPA-mediated survival by only $\sim 50 \%$. Our results are consistent with those of Shi et al., in which rapamycin alone induced limited apoptosis, while rapamycin in conjunction with a second apoptotic stimulus led to enhanced cell death (73). In contrast, TPCK and TLCK, two additional inhibitors of pp $70^{\mathrm{s} 6 \mathrm{k}}$ (51), completely inhibited LPA-mediated macrophage survival and did so at concentrations for which $\sim 50 \%$ of pp $70^{\mathrm{s} 6 \mathrm{k}}$ activity should still be intact. These combined data suggest that PI3K mediates macrophage survival through both $p p 70^{s 6 k_{-}}$ dependent and -independent signaling pathways. In light of recent reports showing that activation of Akt plays a crucial role in survival factor-mediated inhibition of apoptosis (44, 48-50), the most economical interpretation of our data is that PI3K mediates survival through both $\mathrm{pp} 70^{\mathrm{s} 6 \mathrm{k}}$ and Akt. Rapamycin only partially inhibits the effect of LPA, since it inhibits pp70 $0^{\mathrm{s} 6 \mathrm{k}}$ but not Akt. TPCK and TLCK inhibit $\mathrm{pp} 70^{\mathrm{s} 6 \mathrm{k}}$ and other pathways, which perhaps include downstream effectors of Akt.

Although the identity of the TPCK/TLCK-dependent pathways remains unknown, recent data suggest an IкB-dependent mechanism. TPCK and TLCK differ from rapamycin in their ability to block phosphorylation of IкB and thereby prevent nuclear translocation of $\mathrm{NF \kappa B}$ (51). Because NFkB is important in preventing apoptosis (74-76), it is possible that inhi- bition of NFKB translocation by TPCK and TLCK represents the $\mathrm{pp} 70^{\mathrm{s} 6 \mathrm{k}}$-independent survival pathway whose inhibition is necessary for induction of apoptosis.

In conclusion, we have shown that LPA is a major survival factor in FBS. Most known serum survival factors, with the exception of PDGF and IGF-1, occur at concentrations far below those necessary for their survival effects. In contrast, LPA at physiologically relevant doses was equivalent to FBS in maintaining macrophage viability. Moreover, our identification of LPA as a potent survival factor may explain a puzzling aspect of the study by Yao and Cooper, who were the first to show that survival factors such as insulin, EGF, and FBS act through PI3K to prevent apoptosis (27). These authors found that the $\mathrm{IC}_{50}$ of wortmannin needed to inhibit the survival capacity of FBS was 10 times greater than that needed for insulin and EGF. This difference in $\mathrm{IC}_{50}$ 's implies the existence in FBS of additional survival factors that activate PI3K isoforms less sensitive to wortmannin, for example, the p110y isoform activated by LPA. Importantly, we have shown that LPA and FBS share the same $\mathrm{IC}_{50}$ for wortmannin. Taken together, our results suggest that LPA represents a previously unrecognized and major noncytokine serum survival factor.

\section{Acknowledgments}

The authors are grateful to Dr. Ronald McCaffrey for use of his microELISA plate reader and to Tracey Russo for her generous assistance and graphics expertise.

This work was supported by National Institutes of Health grants AR/AI-42732 (J.S. Levine), DK-375105 (W. Lieberthal), and HL53031 (W. Lieberthal); and a Young Investigator Award from the National Kidney Foundation (J.S. Levine).

\section{References}

1. Majno, G., and I. Joris. 1995. Apoptosis, oncosis, and necrosis. Am. J. Pathol. 146:3-15.

2. Raff, M.C. 1992. Social controls on cell survival and cell death. Nature. 356:397-400.

3. Lieberthal, W., and J.S. Levine. 1996. Mechanisms of apoptosis and its potential role in renal tubular epithelial cell injury. Am. J. Physiol. 271 (Renal Fluid Electrolyte Physiol. 40):F477-F488.

4. Steller, H. 1995. Mechanisms and genes of cellular suicide. Science. 267: 1445-1449.

5. Savill, J., V. Fadok, P. Henson, and C. Haslett. 1993. Phagocyte recognition of cells undergoing apoptosis. Immunol. Today. 14:131-136.

6. Evan, G.I., A.H. Wyllie, C.S. Gilbert, T.D. Littlewood, H. Land, M. Brooks, C.M. Waters, L.Z. Penn, and D.C. Hancock. 1992. Induction of apoptosis in fibroblasts by c-myc protein. Cell. 69:119-128.

7. Thompson, E.B. 1994. Apoptosis and steroid hormones. Mol. Endocrinol. 8:665-673.

8. Duke, R.C., and J.J. Cohen. 1986. IL-2 addiction: withdrawal of growth factor activates a suicide program in dependent T cells. Lymphokine Res. 5: 289-299.

9. Becker, S., M.K. Warren, and S. Haskill. 1987. Colony-stimulating factorinduced monocyte survival in differentiation into macrophages in serum-free cultures. J. Immunol. 139:3703-3709.

10. Mangan, D.F., G.R. Welch, and S.M. Wahl. 1991. Lipopolysaccharide, tumor necrosis factor- $\alpha$, and IL-1 $\beta$ prevent programmed cell death (apoptosis) in human peripheral blood monocytes. J. Immunol. 146:1541-1546.

11. Moolenaar, W.H. 1995. Lysophosphatidic acid, a multifunctional phospholipid messenger. J. Biol. Chem. 270:12949-12952.

12. Moolenaar, W.H. 1995. Lysophosphatidic acid signalling. Curr. Opin. Cell Biol. 7:203-210.

13. Jalink, K., P.L. Hordijk, and W.H. Moolenaar. 1994. Growth factor-like effects of lysophosphatidic acid, a novel lipid mediator. Biochim. Biophys. Acta. 1198:185-196.

14. Eichholtz, T., K. Jalink, I. Fahrenfort, and W.H. Moolenaar. 1993. The bioactive phospholipid lysophosphatidic acid is released from activated platelets. Biochem. J. 291:677-680.

15. Tokumura, A., M. Iimori, Y. Nishioka, M. Kitahara, M. Sakashita, and S. Tanaka. 1994. Lysophosphatidic acids induce proliferation of cultured vascu- 
lar smooth muscle cells from rat aorta. Am. J. Physiol. 267 (Cell Physiol. 36): C204-C210.

16. Tigyi, G., and R. Miledi. 1992. Lysophosphatitades bound to serum albumin activate membrane currents in Xenopus oocytes and neurite retraction in PC12 pheochromocytoma cells. J. Biol. Chem. 267:21360-21367.

17. Thumser, A.E.A., J.E. Voysey, and D.C. Wilton. 1994. The binding of lysophospholipids to rat liver fatty acid-binding protein and albumin. Biochem. J. 301:801-806.

18. Benton, A.M., J.M. Gerrard, T. Michiel, and S.E. Kindom. 1982. Are lysophosphatidic acids or phosphatidic acids involved in stimulus activation coupling in platelets? Blood. 60:642-649.

19. Tigyi, G., D.L. Dyer, and R. Miledi. 1994. Lysophosphatidic acid possesses dual action in cell proliferation. Proc. Natl. Acad. Sci. USA. 91:1908-1912.

20. van Corven, E.J., A. Groenink, K. Jalink, T. Eichholtz, and W.H. Moolenaar. 1989. Lysophosphatidate-induced cell proliferation: identification and dissection of signaling pathways mediated by G proteins. Cell. 59:45-54.

21. van Corven, E.J., A. van Rijswijk, K. Jalink, R.L. van der Bend, W.J. van Blitterswijk, and W.H. Moolenaar. 1992. Mitogenic action of lysophosphatidic acid and phosphatidic acid on fibroblasts. Biochem. J. 281:163-169.

22. Ridley, A.J., and A. Hall. 1992. The small GTP-binding protein rho regulates the assembly of focal adhesions and actin stress fibers in response to growth factors. Cell. 70:389-399.

23. van der Bend, R.L., J. Brunner, K. Jalink, E.J. van Corven, W.H. Moolenaar, and W.J. van Blitterswijk. 1992. Identification of a putative membrane receptor for the bioactive phospholipid, lysophosphatidic acid. EMBOJ. 11:2495-2501.

24. Thomson, F.J., L. Perkins, D. Ahern, and M. Clark. 1994. Identification and characterization of a lysophosphatidic acid receptor. Mol. Pharmacol. 45: $718-728$

25. Hecht, J.H, J.A. Weiner, S.R. Post, and J. Chun. 1996. Ventricular zone gene-1 (vzg-1) encodes a lysophosphatidic acid receptor expressed in neurogenic regions of the developing cerebral cortex. J. Cell Biol. 135:1071-1083.

26. Guo, Z., K. Liliom, D.J. Fischer, I.C. Bathurst, L.D. Tomei, M.C. Kiefer, and G. Tigyi. 1996. Molecular cloning of a high-affinity receptor for the growth factor-like lipid mediator lysophosphatidic acid from Xenopus oocytes. Proc. Natl. Acad. Sci. USA. 93:14367-14372.

27. Yao, R., and G.M. Cooper. 1995. Requirement for phosphatidylinositol-3 kinase in the prevention of apoptosis by nerve growth factor. Science. 267:20032006.

28. Jalink, K., E.J. van Corven, and W.H. Moolenaar. 1990. Lysophosphatidic acid, but not phosphatidic acid, is a potent $\mathrm{Ca}^{2+}$-mobilizing stimulus for fibroblasts. Evidence for an extracellular site of action. J. Biol. Chem. 265:1223212239.

29. Levine, J.S., B.J. Pugh, D. Hartwell, J.M. Fitzpatrick, A. Marshak-Rothstein, and D.I. Beller. 1993. IL-1 dysregulation is an intrinsic defect in macrophages from MRL autoimmune-prone mice. Eur. J. Immunol. 23:2951-2958.

30. Price, B.E., J. Rauch, M.A. Shia, M.T. Walsh, W. Lieberthal, H.M. Gilligan, T. O'Laughlin, J.S. Koh, and J.S. Levine. 1996. Antiphospholipid autoantibodies bind to apoptotic, but not nonapoptotic, thymocytes in a $\beta 2$-glycoprotein I-dependent manner. J. Immunol. 157:2201-2208.

31. Mossman, T. 1983. Rapid colorimetric assay for cellular growth and survival: application to proliferation and cytotoxicity assays. J. Immunol. Meth. 65: $55-63$.

32. Hardy, R.W. 1986. Purification and characterization of monoclonal antibodies. In Handbook of Experimental Immunology. D.M. Weir, L.A. Herzenberg, C. Blackwell, and L.A. Herzenberg, editors. Blackwell Scientific Publications, Oxford. 13.1-13.13.

33. Goldstein, J.L., S.K. Basu, and M.S. Brown. 1983. Receptor-mediated endocytosis of low-density lipoprotein in cultured cells. 1983. Methods Enzymol. 98:241-260.

34. Frisch, S.M., and E. Ruoslahti. 1997. Integrins and anoikis. Curr. Opin. Cell Biol. 9:701-706.

35. Saifer, A., and L. Goldman. 1961. The free fatty acids bound to human serum albumin. J. Lipid Res. 2:268-270.

36. Naito, M., S. Umeda, T. Yamamoto, H. Moriyama, H. Umezu, G. Hasegawa, H. Usuda, L.D. Schultz, and K. Takahashi. 1996. Development, differentiation, and phenotypic heterogeneity of murine tissue macrophages. J. Leuk. Biol. 59:133-138.

37. Betsholtz, C., A. Johnsson, C.-H. Heldin, and B. Westermark. 1986. Efficient reversion of simian sarcoma virus-transformation and inhibition of growth factor-induced mitogenesis by suramin. Proc. Natl. Acad. Sci. USA. 83: 6440-6444.

38. Minshall, C., S. Arkins, G.G. Freund, and K.W. Kelley. 1996. Requirement for phosphatidylinositol $3^{\prime}$ kinase to protect hemopoietic progenitors against apoptosis depends upon the extracellular survival factor. J. Immunol. 156:939-947.

39. Zamorano, J., H.Y. Wang, L.-M. Wang, J.H. Pierce, and A.D. Keegan. 1996. IL-4 protects cells from apoptosis via the insulin receptor substrate pathway and a second independent signaling pathway. J. Immunol. 157:4926-4934.

40. Ui, M., T. Okada, K. Hazeki, and O. Hazeki. 1995. Wortmannin as a unique probe for an intracellular signalling protein phophoinositide 3-kinase. Trends Biochem. Sci. 20:303-307.
41. Vlahos, C.J., W.F. Matter, K.Y. Hui, and R.F. Brown. 1994. A specific inhibitor of phosphatidylinositol 3-kinase, 2-(4-Morpholinyl)-8-phenyl-4H-1benzopyran-4-one (LY294002). J. Biol. Chem. 269:5241-5248.

42. King, W.G., M.D. Mattaliano, T.O. Chan, P.N. Tsichlis, and J.S. Brugge, Phosphatidylinositol 3-kinase is required for integrin-stimulated AKT and Raf1/mitogen activated protein kinase pathway activation. Mol. Cell. Biol. 17:44064418

43. Chen, H.-C., P.A. Appeddu, H. Isoda, and J.-L. Guan. 1996. Phosphorylation of tyrosine 397 in focal adhesion kinase is required for binding phosphatidylinositol 3-kinase. J. Biol. Chem. 271:26329-26334.

44. Khwaja, A., P. Rodriguez-Viciana, S. Wennström, P.H. Warne, and J. Downward. 1997. Matrix adhesion and Ras transformation both activate a phosphoinositide 3-OH kinase and protein kinase B/Akt cellular survival pathway. EMBO J. 16:2783-2793.

45. Weng, Q.-P., K. Andrabi, A. Klippel, M.T. Kozlowski, L.T. Lewis, and J. Avruch. 1995. Phosphatidylinositol 3-kinase signals activation of p70 S6 kinase in situ through site-specific p70 phosphorylation. Proc. Natl. Acad. Sci. USA. 92:5744-5748.

46. Chou, M.M., and J. Blenis. 1995. The 70kDa S6 kinase: regulation of a kinase with multiple roles in mitogenic signalling. Curr. Opin. Cell Biol. 7:806814

47. Chung, J., C.J. Kuo, G.R. Crabtree, and J. Blenis. 1992. RapamycinFKBP specifically blocks growth-dependent activation and signaling by the 70 kd S6 protein kinases. Cell. 69:1227-1236.

48. Dudek, H., S.R. Datta, T.F. Franke, M.J. Birnbaum, R. Yao, G.M. Cooper, R.A. Segal, D.R. Kaplan, and M.E. Greenberg. 1997. Regulation of neuronal survival by the serine-threonine kinase Akt. Science. 275:661-665.

49. del Peso, L., M. González-García, C. Page, R. Herrera, and G. Nuñez. 1997. Interleukin-3-induced phosphorylation of BAD through the protein kinase Akt. Science. 278:687-689.

50. Datta, S.R., H. Dudek, X. Tao, S. Masters, H. Fu, Y. Gotoh, and M.E. Greenberg. 1997. Akt phosphorylation of BAD couples survival signals to the cell-intrinsic death machinery. Cell. 231-241.

51. Grammer, T.C., and J. Blenis. 1996. The serine protease inhibitors, tosylphenylalanine chloromethyl ketone and tosyllysine chloromethyl ketone, potently inhibit pp70s6k activation. J. Biol. Chem. 271:23650-23652.

52. Lornage, J., J.F. Guerin, J.C. Czyba, and Y. Menezo. 1983. Influence of cations and albumin on human spermatozoa. Arch. Androl. 10:119-125.

53. Burleson, R.L., D.B. Jones, A.M. Yenikomshian, C. Cornwall, C. DeVoe, and J. DeRito. 1978. Clinical renal preservation by cryoperfusion with an albumin perfusate: renal perfusion with albumin. Arch. Surg. 113:688-692.

54. Guilbert, L.J., and N.N. Iscove. 1976. Partial replacement of serum by selenite, transferrin, albumin and lecithin in haemopoietic cell cultures. Nature. 263:594-595.

55. Kumagai, N., N. Morii, K. Fujisawa, Y. Nemoto, and S. Narumiya. 1993. ADP-ribosylation of rho p21 inhibits lysophosphatidic acid-induced protein tyrosine phosphorylation and phosphatidylinositol 3-kinase activation in cultured Swiss 3 T3 cells. J. Biol. Chem. 268:24535-24538.

56. Carpenter, C.L., and L.C. Cantley. 1996. Phosphoinositide 3-kinase and the regulation of cell growth. Biochim. Biophys. Acta. 1288:M11-M16.

57. Stoyanov, B., S. Volinia, T. Hanck, I. Rubio, M. Loubtchenkov, D Malek, S. Stoyanova, B. Vanhaesebroeck, R. Dhand, B. Nürnberg, P. Gierschik, K. Seedorf, J.J. Hsuan, M.D. Waterfield, and R. Wetzker. 1995. Cloning and characterization of a $\mathrm{G}$ protein-activated human phosphoinositide-3 kinase. Science. 269:690-693.

58. Zhang, J., J. Zhang, J.L. Benovic, M. Sugai, R. Wetzker, I. Gout, and S.E. Rittenhouse. 1995. Sequestration of a G-protein beta gamma subunit or ADP-ribosylation of Rho can inhibit thrombin-induced activation of platelet phosphoinositide 3-kinases. J. Biol. Chem. 270:6589-6594.

59. Stephens, L., A. Smrcka, F.T. Cooke, T.R. Jackson, P.C. Sternweis, and P.T. Hawkins. 1994. A novel phosphoinositide 3 kinase activity in myeloidderived cells is activated by $\mathrm{G}$ protein $\beta \gamma$ subunits. Cell. 77:83-93.

60. Thomason, P.A., S.R. James, P.J. Casey, and C.P. Downes. 1994. A G-protein $\beta \gamma$-subunit-responsive phosphoinositide 3-kinase activity in human platelet cytosol. J. Biol. Chem. 269:16525-16528.

61. Toker, A., and L.C. Cantley. 1997. Signalling through the lipid products of phosphoinositide-3-OH kinase. Nature. 387:673-676

62. Lopez-Ilasaca, M., P. Crespo, P.G. Pellici, J.S. Gutkind, and R. Wetzker. 1996. Linkage of $G$ protein-coupled receptors to the MAPK signaling pathway through PI 3-kinase $\gamma$. Science. 275:394-397.

63. Rodriguez-Viciana, P., P.H. Warne, R. Dhand, B. Vanhaesebroeck, I Gout, M.J. Fry, M.D. Waterfield, and J. Downward. 1994. Phosphatidylinositol 3-OH kinase as a direct target of Ras. Nature. 370:527-532.

64. Lin, T.H., Q. Chen, A. Howe, and R.L. Juliano. 1997. Cell anchorage permits efficient signal transduction between Ras and its downstream kinases. J. Biol. Chem. 272:8849-8852.

65. McNamee, H.P., D.E. Ingber, and M.A. Schwartz. 1993. Adhesion to fibronectin stimulates inositol lipid synthesis and enhances PDGF-induced inositol lipid breakdown. J. Cell Biol. 121:673-678.

66. Chong, L.D., A. Traynor-Kaplan, G.M. Bokoch, and M.A. Schwartz. 1994. The small GTP-binding protein Rho regulates a phosphatidylinositol 4-phosphate 5-kinase in mammalian cells. Cell. 79:507-513. 
67. Franke, T.F., S.-I. Yang, T.O. Chan, K. Datta, A. Kazlauskas, D.K. Morrison, D.R. Kaplan, and P.N. Tsichlis. 1995. The protein kinase encoded by the $A k t$ proto-oncogene is a target of the PDGF-activated phosphatidylinositol 3-kinase. Cell. 81:727-736.

68. Burgering, B.M.Th., and P.J. Coffer. 1995. Protein kinase B (c-Akt) in phosphatidylinositol-3-OH kinase signal transduction. Nature. 376:599-602.

69. Akimoto, K., R. Takahashi, S. Moriya, N. Nishioka, J. Takayanagi, K. Kimura, Y. Fukui, S.-i. Osada, K. Mizuno, S.-i. Hirai, et al. 1996. EGF or PDGF receptors activate atypical $\mathrm{PKC} \lambda$ through phosphatidylinositol 3-kinase. EMBO J. 15:788-798.

70. Toker, A., M. Meyer, K.K. Reddy, J.R. Falck, R. Aneja, S. Aneja, A. Parra, D.J. Burns, L.M. Ballas, and L.C. Cantley. 1994. Activation of protein kinase $\mathrm{C}$ family members by the novel phosphoinositides PtdIns-3,4- $\mathrm{P}_{2}$ and PtdIns-3,4,5-P . J. Biol. Chem. 269:32358-32367.

71. Jefferies, H.B.J., C. Reinhard, S.C. Kozma, and G. Thomas. 1994. Rapa- mycin selectively represses translation of the "polypyrimidine tract" mRNA family. Proc. Natl. Acad. Sci. USA. 91:4441-4445.

72. Brown, E.J., P.A. Beal, C.T. Keith, J. Chen, T.-B. Shin, and S.L. Schreiber. 1995. Control of p70s6 kinase activity of FRAP in vivo. Nature. 377: 441-446.

73. Shi, Y., A. Frankel, L.G. Radvanyi, L.Z. Penn, R.G. Miller, and G.B. Mills. 1995. Rapamycin enhances apoptosis and increases sensitivity to cisplatin in vitro. Cancer Res. 55:1982-1988.

74. Beg, A.A., and D. Baltimore. 1996. An essential role for NF-кB in preventing TNF- $\alpha$-induced cell death. Science. 274:782.

75. Wang, C-Y., M.W. Mayo, and A.S. Baldwin, Jr. 1996. TNF- and cancer therapy-induced apoptosis: potentiation by inhibition of NF-кB. Science. 274 784

76. van Antwerp, D.J., S.J. Martin, T. Kafri, D.R. Green, and I.M. Verma 1996. Suppression of TNF- $\alpha$-induced apoptosis by NF-кB. Science. 274:787. 